\title{
Buoyancy Effects of Steady Laminar Boundary Layer Flow and Heat Transfer over a Permeable Flat Plate Immersed in a Uniform Free Stream with Convective Boundary Condition
}

\author{
Olanrewaju P. O. ${ }^{1, *}$, Titiloye E. O. ${ }^{2}$, Adewale S. O. ${ }^{3}$, Ajadi D. A. ${ }^{4}$ \\ ${ }^{1}$ Department of Mathematics, Covenant University, Ota, Nigeria, West Africa \\ ${ }^{2}$ Department of Mathematics, University of Ilorin, Ilorin. Nigeria \\ ${ }^{3}$ Department of Pure and Applied Mathematics, Ladoke Akintola University of Technology, Ogbomoso \\ ${ }^{4}$ Department of Pure and Applied Physics, Ladoke Akintola University of Technology, Ogbomoso \\ oladapo_anu@yahoo.ie, Philip.olanrewaju@covenantuniversity.edu.ng
}

\begin{abstract}
This study aims at the influence of buoyancy of steady laminar boundary layer flow over a permeable flat plate in a uniform free stream, with the bottom surface of the plate is heated by convection from a hot fluid. Utilizing a similarity variable, the governing nonlinear partial differential equations are first transformed into ordinary differential equations before they are solved numerically by applying shooting iteration technique alongside with sixth-order Runge-Kutta integration scheme. The similarity solutions for the flow and thermal fields are possible if the mass transpiration rate at the surface and the convective heat transfer from the hot fluid on the lower surface of the plate vary like $x^{-1 / 2}$ and the thermal expansion coefficient $\beta$ is proportional to $x^{-1}$. The numerical results are compared with recently known results from the open literature for some particular cases of the present study, to support their validity. The effects of the governing parameters on the flow and thermal fields are investigated.
\end{abstract}

Keywords Boundary Layer, Heat Transfer, Permeable Surface, Local Grashof Number, Convective Parameter, Vertical Plate

\section{Introduction}

Convective flow in porous media has been widely studied in the recent years due to its wide applications in engineering as postaccidental heat removal in nuclear reactors, solar collectors, drying processes, heat exchangers, geothermal and oil recovery, building construction, etc. (Nield and Bejan[1], Ingham and Pop[2], Vafai[3], Vadasz[4], etc.). It is well known that conventional heat transfer fluids, including oil, water, and ethylene glycol mixture are poor heat transfer fluids, since the thermal conductivity of these fluids plays an important role on the heat transfer coefficient between the heat transfer medium and the heat transfer surface. An innovative technique for improving heat transfer by using ultra fine solid particles in the fluids has been used extensively during the last several years.

Laminar boundary layer flow caused by a moving rigid surface was initiated by Sakiadis[5] and later the work was

* Corresponding author:

oladapo_anu@yahoo.ie (Olanrewaju, P. O.)

Published online at http://journal.sapub.org/ajfd

Copyright (C) 2012 Scientific \& Academic Publishing. All Rights Reserved extended to the flow due to stretching of a sheet by Crane[6]. The flow of an incompressible fluid past a moving surface has several engineering applications. The aerodynamic extrusion of plastic sheets, the cooling of a large metallic plate in a cooling bath, the boundary layer along a liquid film in condensation process and a polymer sheet or filament extruded continuously from a die, or a long thread travelling between a feed roll and a wind-up roll are the examples of practical applications of a continuous flat surface. Tsou et al.[7] showed that the Sakiadis flow is physically realizable under laboratory conditions, and they determined the heat transfer rates for certain values of the Prandtl number. The heat transfer part of the above problem was solved by Pohlhausen[8], by assuming plate temperature. Recently, Aziz[9] and Magyari[10] studied the similar problem, but with convective boundary condition. Which was extended by Ishak[11], by introducing the effects of suction and injection on the flat surface, besides giving accurate numerical results for $\operatorname{Pr}=0.1$. Bataller[12] examined radiation effects for the Blasius and Sakiadis flows with a convective surface boundary condition. Makinde and Olanrewaju[13] examined the Buoyancy effects on thermal boundary layer over a vertical plate with a convective surface boundary condition. 
The objective of the present study is to extend the works of Ishak[11], by introducing the effects of buoyancy in the momentum equation and Makinde and Olanrewaju[13], by introducing the effects of suction and injection on the flat surface. The process of suction and injection (blowing) has its importance in many engineering applications such as in the design of thrust bearing and radial diffusers, and thermal oil recovery. Suction is applied to chemical processes to remove reactants. Blowing is used to add reactants, cool the surfaces, prevent corrosion or scaling and reduce the drag (see Labropulu et al.[14]). Similarly, the combined effect of increasing the Prandtl number and the Grashof number reduces the thermal boundary layer thickness along the plate which is vita in engineering applications. To the best knowledge of author, no study appeared to have considered combined effects of suction/injection on the flat plate and buoyancy forces.

\section{Mathematical Formulation}

We consider a steady two-dimensional laminar boundary layer flow over a static permeable flat plate in a viscous fluid of temperature $T_{\infty}$. It is assumed that the free stream moves on the top of the solid surface with a constant velocity $\mathrm{U}_{\infty}$. The boundary layer equations are $[11,13]$ :

$$
\begin{gathered}
\frac{\partial u}{\partial x}+\frac{\partial v}{\partial y}=0, \\
u \frac{\partial u}{\partial x}+v \frac{\partial u}{\partial y}=v \frac{\partial^{2} u}{\partial y^{2}}+g \beta\left(T-T_{\infty}\right), \\
u \frac{\partial T}{\partial x}+v \frac{\partial T}{\partial y}+\alpha \frac{\partial^{2} T}{\partial y^{2}},
\end{gathered}
$$

where $\mathrm{u}$ and $\mathrm{v}$ are the velocity components in the $\mathrm{x}$ and $\mathrm{y}$ directions, respectively, $\mathrm{T}$ is the fluid temperature in the boundary layer, $v$ is the kinematic viscosity, $g$ is the acceleration due to gravity, $\beta$ is the thermal expansion coefficient, and $\alpha$ is the thermal diffusivity.

We shall solve Eqs. (1) and (2) subject to the following boundary conditions:

$$
\begin{array}{ll}
u=0, & v=V_{w}(x), \\
u \rightarrow U_{\infty} & \text { as } \quad y \rightarrow \infty^{\prime}
\end{array}
$$

Where $V_{w}(x)$ is the mass transfer velocity at the surface of the plane with $\mathrm{V}_{\mathrm{w}}(\mathrm{x})>0$ for injection (blowing), $\mathrm{V}_{\mathrm{w}}(\mathrm{x})<0$ for suction and $\mathrm{V}_{\mathrm{w}}(\mathrm{x})=0$ corresponds to an impermeable plate. It is also assumed that the bottom surface of the plate is heated by convection from a hot fluid of temperature $T_{f}$ which provides a heat transfer coefficient $h_{f}$. It is under this assumption that the boundary conditions for the thermal field may be written as[9]:

$$
\begin{aligned}
& -\mathrm{k} \frac{\partial \mathrm{T}}{\partial \mathrm{y}}=\mathrm{h}_{\mathrm{f}}\left(\mathrm{T}_{\mathrm{f}}-\mathrm{T}_{\mathrm{w}}\right) \quad \text { at } \quad \mathrm{y}=0, \\
& \mathrm{~T} \rightarrow \mathrm{T}_{\infty} \quad \text { as } \mathrm{y} \rightarrow \infty,
\end{aligned}
$$

With $\mathrm{k}$ and $\mathrm{T}_{\mathrm{w}}$ being the thermal conductivity and the uniform temperature over the top surface of the plate, re- spectively and also we have $\mathrm{T}_{\mathrm{f}}>\mathrm{T}_{\mathrm{w}}>T_{\infty}$

We introduce a similarity variable $\eta$ and a dimensionless stream function $\mathrm{f}(\eta)$ and $\theta(\eta)$ as

$$
\eta=\left(\frac{U_{\infty}}{v x}\right)^{1 / 2} y, \quad \psi=\left(v x U_{\infty}\right)^{1 / 2} f(\eta), \quad \theta(\eta)=\frac{T-T_{\infty}}{T_{f}-T_{\infty}}
$$

where prime symbol denotes differentiation with respect to $\eta$. Eqs. (1)-(5) reduces to

$$
\begin{gathered}
\mathrm{f}^{\prime \prime \prime}+\frac{1}{2} \mathrm{ff}^{\prime \prime}+\mathrm{Gr}_{\mathrm{x}} \theta=0, \\
\theta^{\prime \prime}+\frac{1}{2} \operatorname{Pr} \mathrm{f} \theta^{\prime}=0 .
\end{gathered}
$$

In order that similarity solutions of Eqs. (1)-(5) exist, we take (see[11],[13]):

$$
\mathrm{V}_{\mathrm{w}}(\mathrm{x})=-\frac{1}{2}\left(\frac{\mathrm{v} \mathrm{U}_{\infty}}{\mathrm{x}}\right)^{1 / 2} \mathrm{f}_{\mathrm{w}}, \quad \mathrm{h}_{\mathrm{f}}=\mathrm{cx}^{-1 / 2}, \quad \beta=1 \mathrm{x}^{-1},
$$

where $c, l$ and $f_{w}(=f(0))$ are constants. It is noteworthy to mention here that $f_{w}$ determines the transpiration rate at the surface, with $f_{w}>0$ for suction, $f_{w}<0$ for injection, and $f_{w}=0$ corresponds to an impermeable surface.

The transformed boundary conditions are:

$$
\begin{array}{ll}
f(0)=f_{w}, & f^{\prime}(0)=0, \quad \theta^{\prime}(0)=-a[1-\theta(0)], \\
f^{\prime}(\eta) \rightarrow 1, & \theta(\eta) \rightarrow 0 \text { as } \quad \eta \rightarrow \infty,
\end{array}
$$

where $a=\frac{c}{k} \sqrt{\frac{v}{U_{\infty}}}$. The assumptions (9) is necessary for the boundary conditions (10) to be independent of $\mathrm{x}$. It is clear that without these assumptions, the generated solutions are the local similarity solutions (see Ishak[11]). We noted that when $a \rightarrow \infty\left(a n d f_{w}=0\right)$, and in the absent of Grashof number the present problems reduces to the classical thermal layer flow on a flat with constant surface temperature considered by Pohlhausen[8]. Similarly if $\mathrm{V}_{\mathrm{w}}(\mathrm{x})=0$ then the present problem reduces to Makinde and Olanrewaju[13]. Finally in the absent of Grashof number the present problem reduces to Ishak[11].

\section{Numerical Procedure}

The set of non-linear ordinary differential equations (7)-(8) with boundary conditions in (10) have been solved numerically by using the sixth-order Runge-Kutta integration scheme with a modified version of the Newton-Raphson shooting method with $\mathrm{Pr}, G r, f_{w}$ and $a$ as prescribed parameters. The computations were done by a program which uses a symbolic and computational computer language MAPLE[15]. A step size of $\Delta \eta=0.001$ was selected to be satisfactory for a convergence criterion of $10^{-7}$ in nearly all cases. The value of $y_{\infty}$ was found to each iteration loop by the assignment statement $\eta_{\infty}=\eta_{\infty}+\Delta \eta$. The maximum value of $\eta_{\infty}$, to each group of parameters $P r, G r, f_{w}$ and $a$ is determined when the values of unknown boundary conditions at $\eta$ $=0$ not change to successful loop with error less than $10^{-7}$.

\section{Results and Discussion}


Here, we assigned physically realistic numerical values to the embedded parameters in the system in order to gain an insight into the flow structure with respect to velocity and temperature profiles. The results are presented graphically in Figures 1-10 and conclusions are drawn for the flow field and other physical quantity of interest that have significant effects. To test the validity of our results, so comparisons of the present results with previously works are performed and excellent agreement has been obtained in Tables 1 and 2 . From Table 3 , it is understood that the increase in convective parameter a, the local Grashof number $G r_{x}$ and suction/injection parameter $f_{w}$ are to increase the skin friction coefficient and heat transfer rate. Also increase in the Prandtl number $\operatorname{Pr}$ is to reduce the skin friction at the plate and increase the heat rate transfer at the wall plate. In many practical applications, the characteristics involved, such as the heat transfer rate at the surface are vital since they influence the quality of the final products.

Figures 1 and 2 represent the influence of the local Grashof number on velocity and temperature fields, respectively. In Figure 1, it was noticed that local Grashof number is to increase the velocity distribution in the boundary layer which leads to thickening of the boundary layer thickness while temperature in the boundary layer decreases with increase in the value of $\mathrm{Gr}_{\mathrm{x}}$ as shown in Figure 2 for impermeable surface. Figures 3 and 4 depict the effect of local Grashof number on the velocity and temperature field for permeable surface. The same influence was established but the velocity and the temperature at the wall plate was maximum for impermeable surface. It was noted that for permeable surface the convergence was rapid compared with the impermeable surface. Figure 5 depicts the velocity solutions for various values of $f_{w}$. We notice that the velocity gradient at the surface which represents the skin friction coefficient increases with increasing $f_{w}$. Thus the surface shear stress is higher for suction compared to injection. Figure 6 represents the temperature profiles for different values of suction/injection parameter $f_{w}$ and it was observed that the heat transfer rate at the surface is higher for suction compared to injection. Infact, it was due to the fact that the surface shear stress increases when suction is introduced, which then in turn increases the local Nusselt number. It was later observed that in the presence of local Grashof number the velocity and temperature solutions reaches zero faster compared to Ishak[11] work in the absence of local Grashof number. To be specific, it reaches zero at $\eta=6.8$ while that of Ishak[11] reaches zero at $\eta=8.5$. The effect of Prandtl number is to reduce the thermal boundary layer thickness which increases in value of Prandtl number as in Figure 7. Increasing the Prandtl number means that slowing the rate of thermal diffusion. Figures 8 to 10 represent the temperature profiles for various values of convective parameter a. It is seen that from Figures 8 to 10 that the surface temperature $\theta(0)$ increases as a increases. From the definition of parameter $a$ at any location $\mathrm{x}$ is directly proportional to the heat transfer coefficient associated with the hot fluid $h_{f}$. It is seen from Figures 8 to 10 that $\theta(0) \rightarrow 0$ as a $\rightarrow \infty$. This case for impermeable surface was first considered by Pohlhausen[8].

Table 1. Computations showing comparison with Aziz[1], Makinde \& Olanrewaju[13] and Ishak[11] results for $\mathrm{Gr}_{\mathrm{x}}=0, \mathrm{f}_{\mathrm{w}}=0$ (impermeable) for $-\theta^{\prime}(0)$ when $\operatorname{Pr}=0.72$

\begin{tabular}{|c|c|c|c|c|}
\hline a & Aziz[9] & $\begin{array}{c}\text { Makinde \& } \\
\text { Olanrewaju[13] }\end{array}$ & Ishak[11] & Present results \\
\hline 0.05 & 0.0428 & 0.0428 & 0.042767 & 0.042766941992484209 \\
\hline 0.10 & 0.0747 & 0.0747 & 0.074724 & 0.074724195214009151 \\
\hline 0.20 & 0.1193 & 0.1193 & 0.119295 & 0.119295494196438630 \\
\hline 0.40 & 0.1700 & 0.1700 & 0.169994 & 0.169994412957404028 \\
\hline 0.60 & 0.1981 & 0.1981 & 0.198051 & 0.198050668962487962 \\
\hline 0.80 & 0.2159 & 0.2159 & 0.215864 & 0.215864006864323970 \\
\hline 1 & 0.2282 & 0.2282 & 0.228178 & 0.228177853286349014 \\
\hline 5 & 0.2791 & 0.2791 & 0.279131 & 0.279131077287059768 \\
\hline 10 & 0.2871 & 0.2871 & 0.287146 & 0.287146220678761388 \\
\hline 20 & 0.2913 & 0.2913 & 0.291329 & 0.291328920605072150 \\
\hline
\end{tabular}

Table 2. Computations showing comparisons with Makinde \& Olanrewaju[13] results for $f_{w}=0$ (impermeable) for $-\theta^{\prime}(0)$ for various embedded flow parameters

\begin{tabular}{|c|c|c|c|c|}
\hline $\mathrm{a}$ & $\mathrm{Gr}_{\mathrm{x}}$ & $\operatorname{Pr}$ & $\begin{array}{c}\text { Makinde \& } \\
\text { Olanrewaju[13] }\end{array}$ & Present results \\
\hline 0.1 & 0.1 & 0.72 & 0.07507 & 0.075077162687329987 \\
\hline 1.0 & 0.1 & 0.72 & 0.23750 & 0.237506157092818748 \\
\hline 10 & 0.1 & 0.72 & 0.30559 & 0.305596432752293646 \\
\hline 0.1 & 0.5 & 0.72 & 0.07613 & 0.076137748064108737 \\
\hline 0.1 & 1.0 & 0.72 & 0.07704 & 0.077044846560947566 \\
\hline 0.1 & 0.1 & 3.00 & 0.08304 & 0.083045987123692544 \\
\hline 0.1 & 0.1 & 7.10 & 0.08672 & 0.086721160479174289 \\
\hline
\end{tabular}

Table 3. Computations showing $\mathrm{f}^{\prime \prime}(0),-\theta^{\prime}(0)$ and $\theta(0)$ for various embedded flow parameters

\begin{tabular}{|c|c|c|c|c|c|c|}
\hline $\mathrm{a}$ & $\mathrm{Gr}_{\mathrm{x}}$ & $\operatorname{Pr}$ & $\mathrm{f}_{\mathrm{w}}$ & $\mathrm{f}^{\prime \prime}(0)$ & $-\theta^{\prime}(0)$ & $\theta(0)$ \\
\hline 0.1 & 0.1 & 0.72 & 0 & 0.368815518866807690 & 0.0750771626873299874 & 0.249228373126700458 \\
\hline 1.0 & 0.1 & 0.72 & 0 & 0.440365295559651482 & 0.2375061570928187480 & 0.762493842907181141 \\
\hline 10 & 0.1 & 0.72 & 0 & 0.467927882847428034 & 0.3055964327522936461 & 0.969440356724770026 \\
\hline 0.1 & 0.5 & 0.72 & 0 & 0.497022154578945774 & 0.0761377480641087373 & 0.238622519358912766 \\
\hline 0.1 & 1.0 & 0.72 & 0 & 0.632007094035491379 & 0.0770448465609475663 & 0.229551534390523976 \\
\hline 0.1 & 0.1 & 3.00 & 0 & 0.349397347069098750 & 0.0830459871236925440 & 0.169540128763074366 \\
\hline 0.1 & 0.1 & 7.10 & 0 & 0.342704996405172046 & 0.0867211604791742892 & 0.132788395208256527 \\
\hline 0.1 & 0.1 & 0.72 & -1 & 0.142839194015394078 & 0.0468428376312674256 & 0.531571623687325801 \\
\hline 0.1 & 0.1 & 0.72 & -0.5 & 0.227584686539569646 & 0.0643250233479395889 & 0.356749766520604138 \\
\hline 0.1 & 0.1 & 0.72 & 0 & 0.368815518866807690 & 0.0750771626873299874 & 0.249228373126700458 \\
\hline 0.1 & 0.1 & 0.72 & 1 & 0.744567932664679022 & 0.0853794261350979967 & 0.146205738649020200 \\
\hline 0.1 & 0.1 & 0.72 & 2 & 1.177773368835239420 & 0.0899465299660448386 & 0.100534700339551183 \\
\hline
\end{tabular}




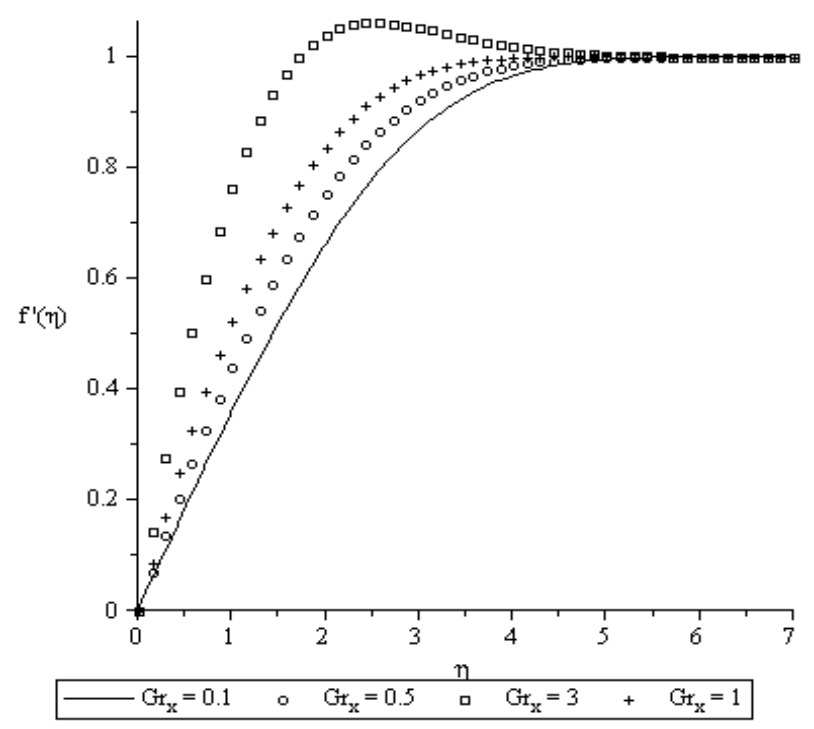

Figure 1. Velocity profiles for $\operatorname{Pr}=0.72, a=0.1, f_{w}=0$ (impermeable)

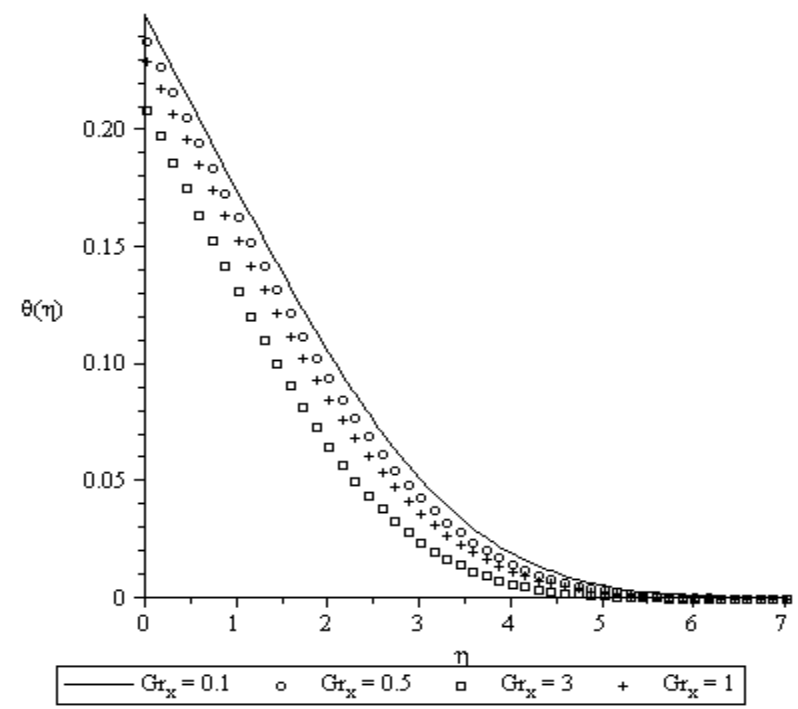

Figure 2. Temperature profiles for $\operatorname{Pr}=0.72, \mathrm{a}=0.1, \mathrm{f}_{\mathrm{w}}=0$ (impermeable)

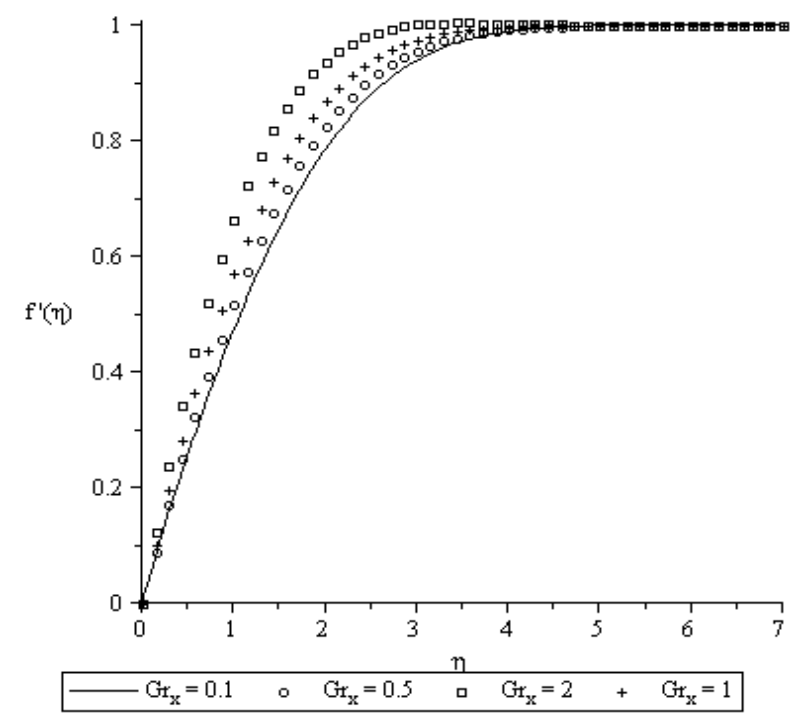

Figure 3. Velocity profiles for $\operatorname{Pr}=0.72, \mathrm{a}=0.1, \mathrm{f}_{\mathrm{w}}=0.5$ (permeable)

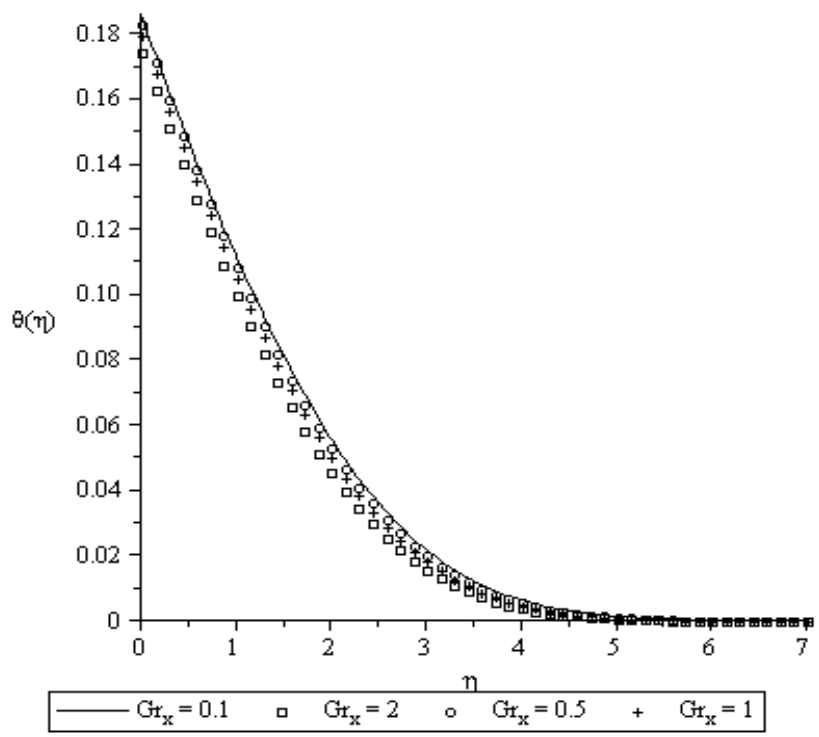

Figure 4. Temperature profiles for $\operatorname{Pr}=0.72, \mathrm{a}=0.1, \mathrm{f}_{\mathrm{w}}=0.5$ (permeable)

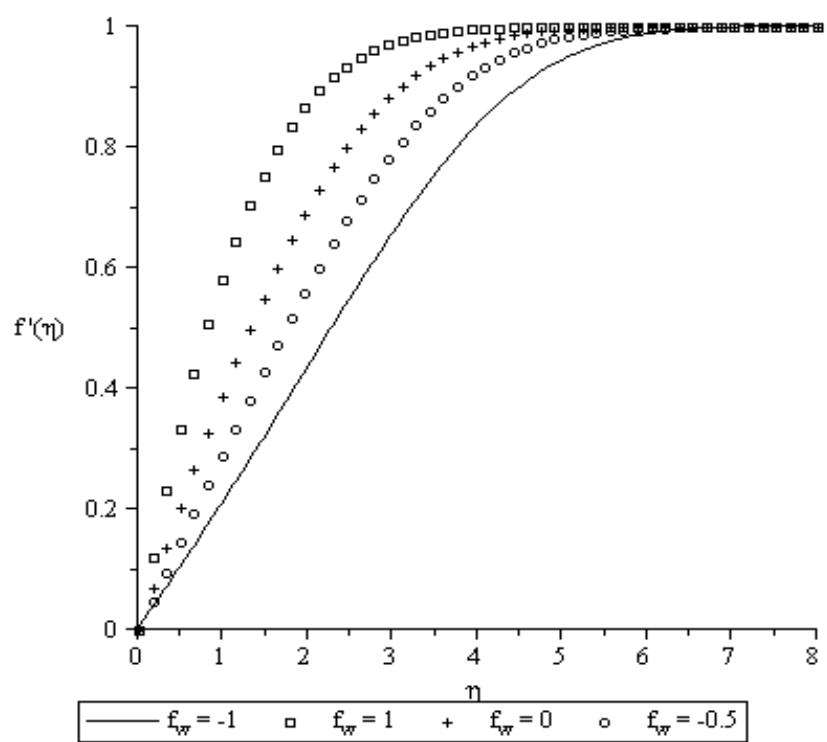

Figure 5. Velocity profiles for $\operatorname{Pr}=1, \mathrm{a}=1, \mathrm{Gr}_{\mathrm{x}}=0.1$

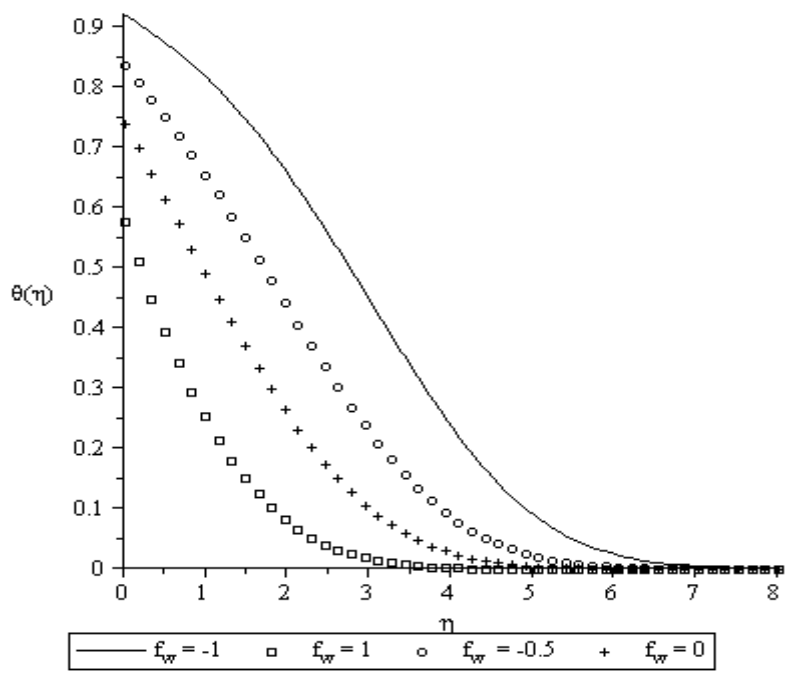

Figure 6. Temperature profiles for $\operatorname{Pr}=1, \mathrm{a}=1, \mathrm{Gr}_{\mathrm{x}}=0.1$ 


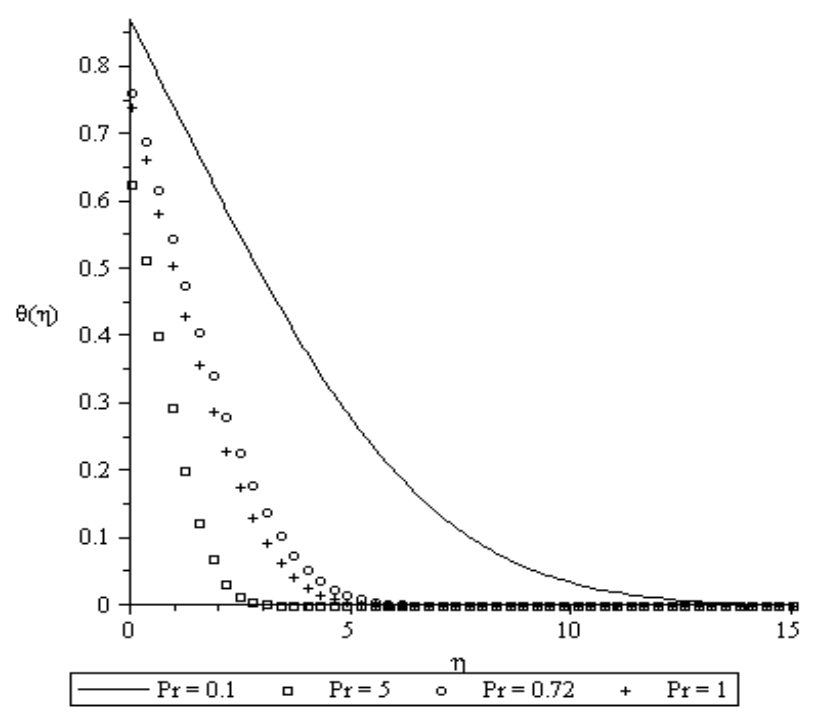

Figure 7. Temperature profiles for $\mathrm{f}_{\mathrm{w}}=0, \mathrm{a}=1, \mathrm{Gr}_{\mathrm{x}}=0.1$

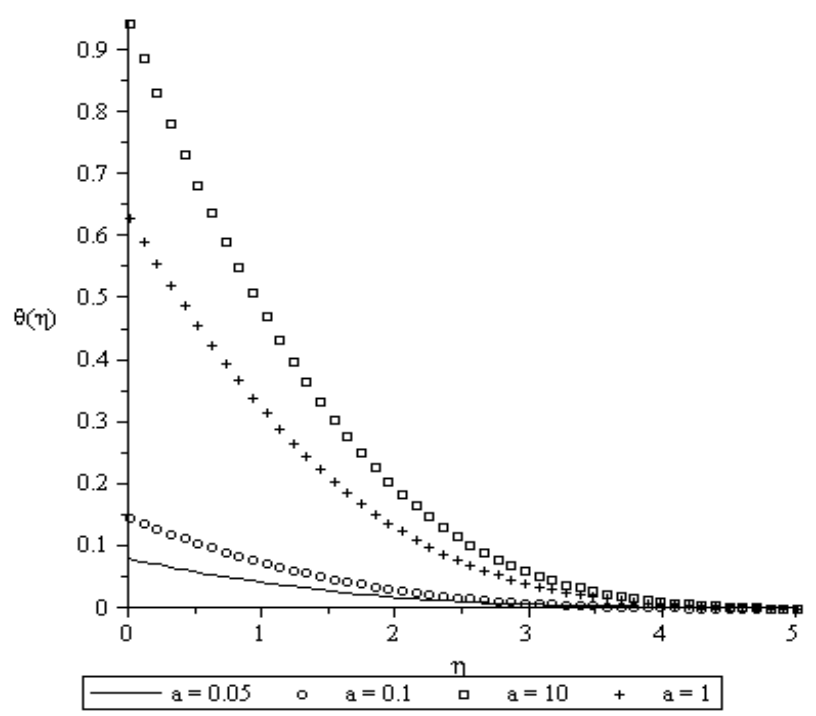

Figure 8. Temperature profiles for $\mathrm{f}_{\mathrm{w}}=1, \operatorname{Pr}=0.72, \mathrm{Gr}_{\mathrm{x}}=0.1$

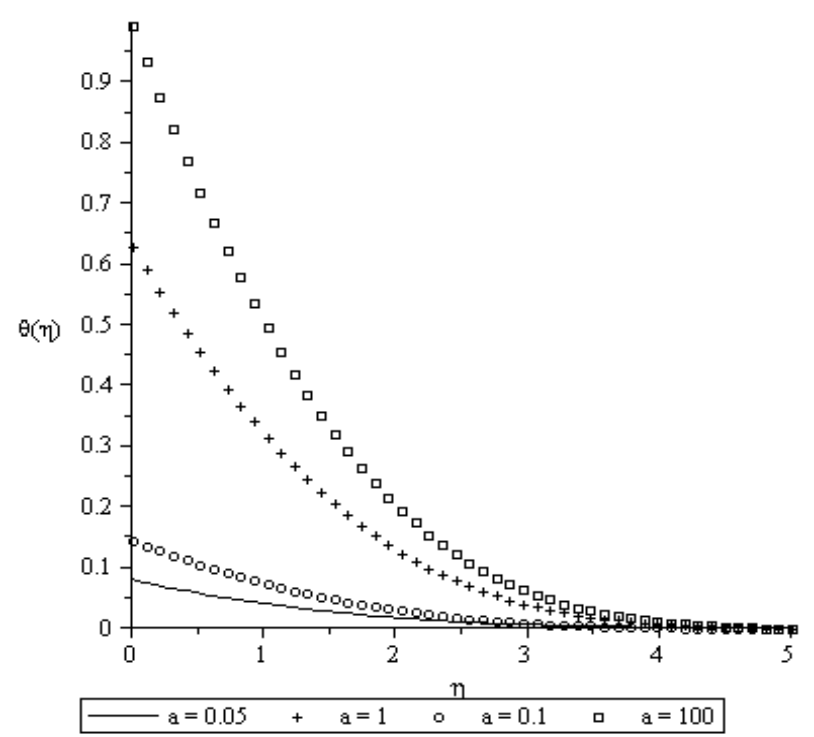

Figure 9. Temperature profiles for $\mathrm{f}_{\mathrm{w}}=1, \operatorname{Pr}=0.72, \mathrm{Gr}_{\mathrm{x}}=0.1$

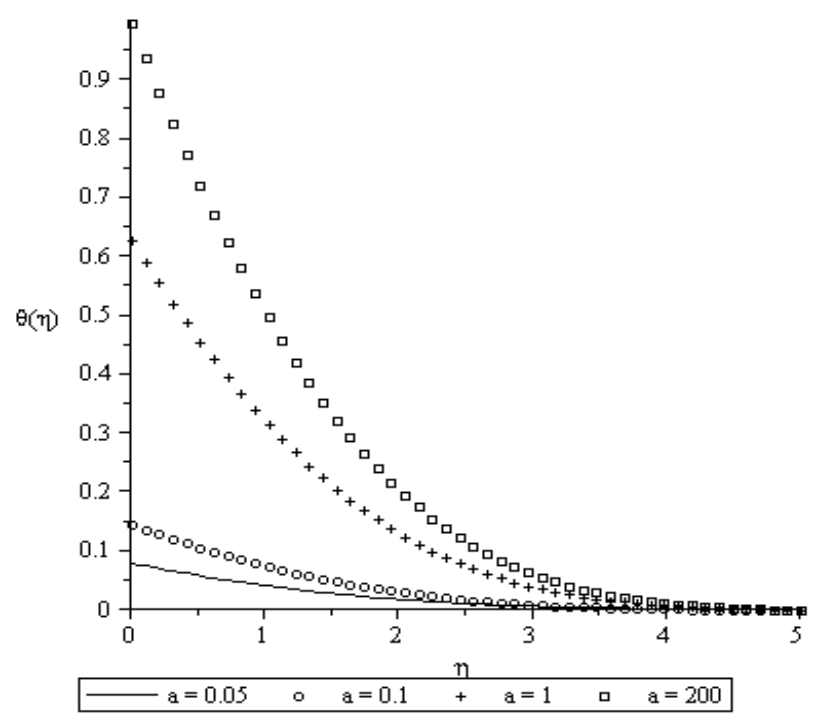

Figure 10. Temperature profiles for $\mathrm{f}_{\mathrm{w}}=1, \operatorname{Pr}=0.72, \mathrm{Gr}_{\mathrm{x}}=0.1$

\section{Conclusions}

We studied theoretically the problem of steady laminar boundary flow and heat transfer over a stationary permeable flat immersed in a uniform free stream in the presence of buoyancy forces with convective boundary condition. The similarity solutions are possible if the convective heat transfer from the lower surface and the mass transpiration rate at the surface vary like $x^{-1 / 2}$ and thermal expansion coefficient is directly proportional to $x^{-1}$, where $\mathrm{s}$ is the distance from the leading edge of the solid surface. It was found that the combined effect of suction and local Grashof number increases the surface shear stress and as a consequence increases the heat transfer rate at the plate.

\section{ACKNOWLEDGEMENTS}

Dr. Olanrewaju wishes to express his gratitude to the financial support of Covenant University, Ota, Nigeria, West Africa on this research work.

\section{REFERENCES}

[1] D.A. Nield, A. Bejan, Convection in Porous Media, third ed., Springer, New York, 2006.

[2] D.B. Ingham, I. Pop (Eds.), Transport Phenomena in Porous Media, Vol. III, Elsevier, Oxford, 2005.

[3] K. Vafai (Ed.), Handbook of Porous Media, second ed., Taylor \& Francis, New York, 2005.

[4] P. Vadasz, Emerging Topics in Heat and Mass Transfer in Porous Media, Springer, New York, 2008.

[5] B.C. Sakiadis, Boundary-layer behavior on continuous solid surfaces. I. Boundary-layer equations for two-dimensional 
and axisymmetric flow, AIChE J. 7 (1961) 26-28; Boundary-layer behavior on continuous solid surfaces. II. The boundary-layer on a continuous flat surface, AIChE J. 7 (1961) 221-225.

[6] I.J. Crane, Flow past a stretching plate, Z. Angew. Math. Phys. $21(56)(1970) 1-37$.

[7] F.K. Tsou, E.M. Sparrow, R.J. Glodstein, Flow and heat transfer in the boundary layer on a continuous moving surface, Int. J. Heat Mass Transfer 10 (1967) 219-235.

[8] E. Pohlhausen, der wärmeaustausch zwischen festen körpern und flüssigkeiten mit kleiner reibung und kleiner wärmeleitung, Z. Angew. Math. Mech. 1 (1921) 115-121.

[9] A. Aziz, A similarity solution for laminar thermal boundary layer over a flat plate with a convective surface boundary condition, Commun. Nonlinear Sci. Numer. Simul. 14 (2009) 1064-1068.

[10] E. Magyari, Comment on "A similarity solution for laminar thermal boundary layer over a flat plate with a convective surface boundary condition" by A. Aziz, Nonlinear Sci. Numer. Simul. 142009 1064-1068, Nonlinear Sci. Numer. Simul. (2010), doi:10.1016/j.cnsns.2010.03.020.

[11] A. Ishak, Similarity solutions for flow and heat transfer over a permeable surface with convective boundary condition, Applied Mathematics and Computation 217 (2010) 837-842.

[12] R.C. Bataller, Radiation effects for the Blasius and Sakiadis flows with a convective surface boundary condition, Applied Mathematics and Computation 2006 (2008) 832-840.

[13] O.D. Makinde and P.O. Olanrewaju, Buoyancy effects on thermal boundary layer over a vertical plate with a convective surface boundary condition, ASME Journal of Fluid Engineering 132 (2010) 044502 1-4.

[14] F. Labropulu, J.M. Dorrepaal, O.P. Chandna, Oblique flow impinging on a wall with suction or blowing, Acta Mech. 115 (1996) 15-25.

[15] A. Heck, Introduction to Maple, 3rd Edition, Springer-Verlag, (2003). 